\title{
Los proyectos especiales de inversión pública y el modelo de ejecución de inversiones públicas: revisión de las herramientas que pueden emplearse para mejorar las contrataciones del Estado(*)
}

\author{
Special public investment projects and the public investment execution \\ model: review of the tools that can be used to improve government \\ contracting
}

\author{
Juan Carlos Medina Flores ${ }^{(* *}$ \\ Estudio Echecopar Asociado a Baker \& McKenzie International (Lima, Perú)
}

\begin{abstract}
Resumen: En el año 2019 se llevaron a cabo en Lima los XVIII Juegos Panamericanos y Sextos Juegos Parapanamericanos. Este fue el mayor evento deportivo multidisciplinario organizado por el Perú. Este evento fue un gran reto para el Perú, tanto por su complejidad como por el corto tiempo con el que se contaba para su ejecución. Para cumplir sus objetivos, el Proyecto Especial a cargo de la organización de los Juegos empleó diferentes mecanismos de contratación y herramientas de gestión novedosos, dentro del marco de un contrato de Gobierno a Gobierno con el Reino Unido. En este contexto, estas experiencias han sido replicadas en un nuevo Modelo de Ejecución de Inversiones Públicas que puede ser empleado por los Proyectos Especiales de Inversión Pública. Lo que se busca mediante este nuevo esquema es destrabar las inversiones públicas, gestionándolas y ejecutándolas eficientemente, empleando altos estándares internacionales.
\end{abstract}

La regulación de estos Proyectos Especiales de Inversión Pública se ha venido desarrollando progresivamente en el último año, incorporando incluso la posibilidad de celebrar contratos de Gobierno a Gobierno. A la fecha, se encuentra en operación el Proyecto de Inversión Pública, denominado "Escuelas Bicentenario", que permitirá analizar el funcionamiento de este nuevo Modelo de Ejecución de Inversiones Públicas. Actualmente, en medio de constantes anuncios de modificación de la Ley de Contrataciones del Estado, se ha puesto sobre la mesa la discusión de la oportunidad y pertinencia de implementar varias de las herramientas del Modelo de Ejecución de Inversiones en la normativa de contrataciones del Estado, a efectos de mejorar la ejecución de las obras públicas. En este escenario, es importante conocer estas herramientas comprendidas en el Modelo de Ejecución de Inversiones Públicas como punto de partida para evaluar posibles propuestas de mejora a la normativa de contrataciones del Estado, ya sea para prever nuevas figuras o para mejorar la regulación existente. Para dicho fin, en el presente artículo se reseñan algunas de las principales herramientas

(*) Nota del editor: El artículo fue recibido el 04 de abril de 2021 y su publicación fue aprobada el 21 de junio de 2021.

${ }^{(* *}$ Abogado por la Universidad San Martín de Porres. Máster en Contratación Pública y estudios de postgrado en Derecho de la Construcción, Derecho Corporativo y Arbitraje. Miembro de la Sociedad Peruana de Derecho de la Construcción y de la Asociación Latinoamericana de Derecho de la Construcción. Presidente de la Comisión de Contrataciones del Estado de la Sociedad Peruana de Derecho. Asociado Senior del Estudio Echecopar, asociado a Baker \& Mckenzie International. ORCID: https://orcid.org/00000003-1887-2619. Correo electrónico: juancarlos.medina@bakermckenzie.com. 
del Modelo de Ejecución de Inversiones Públicas, así como los beneficios que estas podrían aportar para la ejecución de las obras públicas.

Palabras claves: Proyectos Especiales de Inversión Pública - Contratos de Gobierno a Gobierno - Contratos Estándares Internacionales - Modelo de Ejecución de Inversiones Públicas Infraestructura Pública

Abstract: After the XVIII Pan American Games and Sixth Parapan American Games were held between July and September 2019, the largest sporting event organized and executed by Peru, which involved the deployment of novel contracting and management mechanisms, the Government has sought replicate this experience in a new investment management model. In this context, the Special Public Investment Projects were created, with the aim of applying this new investment management model for the execution of public investment projects, a package of projects or a portfolio of projects.

The regulation of these Special Public Investment Projects has been progressively developed in the last year, adopting even the mechanism of Government-to-Government contracts. This regulatory development has led to the creation of the first Public Investment Project, "Escuelas Bicentenario". With the constant announcements of modification of the Government Procurement Law, the discussion of the opportunity and relevance of implementing the tools enabled for Special Public Investment Projects in the general regulation of public contracts has been raised, in order to improve the execution of public works. In this scenario, it is important to study the tools considered in the investment execution model envisaged in Emergency Decree 0212020 , as a starting point to evaluate the proposals for improvement to the Government Procurement Law. In this article the main tools of the Investment Execution Model are reviewed, as well as the benefits these tools provide for the execution of important infrastructure projects in Peru.

Keywords: Special Public Investment Projects - Government to Government Contracts - International Standard Contracts Investment Model - Public Infrastructure

\section{Presentación del tema}

En el marco del empleo de los Contratos de Gobierno a Gobierno para la ejecución de importantes proyectos de inversión pública, el Estado ha venido empleando nuevas herramientas en gestión de proyectos y ejecución de obras públicas. De esta manera, poco a poco los funcionarios públicos involucrados en estos proyectos vienen ganando una importante experiencia que podría ser replicada directamente por las
Entidades públicas, sin tener que recurrir necesariamente a la contratación entre Estados. Siguiendo este camino, mediante Decreto de Urgencia 021-2020 se regularon los Proyectos Especiales de Inversión Pública (en adelante, los "PEIP") y un Modelo de Ejecución de Inversiones Públicas que recoge las herramientas empleadas por el Proyecto Especial a cargo de los Juegos Panamericanos y las buenas prácticas internacionales, que permitan ejecutar eficientemente las obras públicas, evitando sobrecostos, demoras y controversias en que se ven entrampadas actualmente con la normativa de contrataciones del Estado.

De esta manera, los PEIP son un buen punto de partida para probar nuevas herramientas de gestión de proyectos para evaluar su aplicabilidad y ventajas, así como los retos y oportunidades de mejora, e ir generando capacidades nacionales, para luego, sobre la base de evidencias, determinar la viabilidad de incluir estas herramientas en la normativa general de contratación pública. A la fecha solo se encuentra en funciones el PEIP "Escuelas Bicentenario", pero mientras más se desarrollen este tipo de organizaciones, se contará con mayor información respecto de los beneficios y retos en el uso del Modelo de Ejecución de Inversiones Públicas, para la adopción de decisiones normativas eficientes. Paralelamente, en el último año, el Gobierno viene impulsando reformas normativas tendientes a implementar algunas de estas herramientas en la contratación pública nacional ${ }^{(1)}$ o mejorar su regulación. En este contexto, resulta importante evaluar a detalle las experiencias adquiridas en el marco de los Contratos de Gobierno a Gobierno, así como aquellas que se generen con el desarrollo de Ios PEIP, para tener mayores elementos de juicio para promover reformas sustanciales en la normativa de contratación pública.

En el presente artículo se reseñan algunas de las principales herramientas del Modelo de Ejecución de Inversiones Públicas empleado por los PEIP, señalando sus beneficios y el uso que han tenido en proyectos públicos previos.

(1) Por ejemplo, se prepublicó el Proyecto de Ley de la Cadena de Abastecimiento Público y, posteriormente, un Proyecto de Nueva Ley de Contrataciones del Estado. 
Los proyectos especiales de inversión pública y el modelo de ejecución de inversiones públicas: revisión de las herramientas que pueden emplearse para mejorar las contrataciones del Estado

Special public investment projects and the public investment execution model: review of the tools that can be used to improve government contracting

\section{Los Proyectos Especiales de Inversión Pública}

Mediante Decreto de Urgencia 021-2020 (en adelante, el "DU 021-2020") se regularon los Proyectos Especiales de Inversión Pública (PEIP). De acuerdo con el Reglamento de dicha norma, aprobado mediante Decreto Supremo 119-2020-EF, Ios PEIP son una estructura organizativa creada para la ejecución de un proyecto de inversión, un programa de inversión o una Cartera de Inversiones de naturaleza sectorial o multisectorial, que tienen como objetivo ejecutar inversiones viables o aprobadas, sostenibles y que cuentan con disponibilidad presupuestal para su ejecución y funcionamiento. Los PEIP tienen carácter temporal, de manera tal que, una vez cumplidos sus objetivos, los activos de las inversiones ejecutadas se integran a la Entidad responsable de la fase de funcionamiento de las inversiones.

Los PEIP se crean mediante solicitud, dirigida por la Entidad del Poder Ejecutivo de la que estos dependerán, dirigida al Ministerio de Economía y Finanzas y su máxima autoridad es un Director Ejecutivo designado mediante resolución ministerial de la Entidad responsable del PEIP. Para que un proyecto de inversión se incorpore a un PEIP, debe contar con declaración de viabilidad y encontrarse registrado en el Programa Multianual de Inversiones; debe ser rentable y sostenible; tener un monto total de inversión a precios de mercado igual o mayor a 600,000 UIT; determinar la magnitud del cierre de brechas de infraestructura y de acceso a los servicios públicos.

En el caso que se incorpore al PEIP una cartera de inversiones, las inversiones que la componen deben encontrarse en un estado homogéneo para su empaquetamiento, así como cumplir con alguno de los siguientes criterios:

a) Las inversiones mejoran los niveles de servicios relacionados entre sí.

b) Las inversiones requieren un nivel de tecnología homogénea y/o especializada.

c) Las inversiones coinciden en un mismo espacio territorial o se encuentran colindantes.

d) Las inversiones forman parte de una red de servicios.

Adicionalmente, los proyectos de inversión o las inversiones que componen la cartera deben contar con saneamiento físico legal; no tener contratos vigentes relacionados directamente con la ejecución física de la obra o infraestructura y no tener controversias o arbitrajes vigentes relacionados directamente con la ejecución física de la obra o infraestructura.

Como puede advertirse, se busca incorporar a los PEIP proyectos que no se encuentren paralizados o con contingencias, pues de ser así no funcionaría eficientemente el Modelo de Ejecución de Inversiones Públicas. Solo proyectos que se encuentren libres para una rápida ejecución, obteniendo el mayor provecho de las herramientas y facilidades del Modelo de Ejecución de Inversiones Públicas pueden ser incorporados al PEIP; de otro modo, se invertiría en crear toda una estructura organizativa, con su propio personal y recursos, que no podría cumplir con sus funciones eficientemente.

Estos PEIP, como se ha mencionado anteriormente, a través del Modelo de Ejecución de Inversiones Públicas que se les ha habilitado, tienen la posibilidad de emplear una serie de herramientas y estándares internacionales de gestión de inversiones para ejecutar proyectos de inversión pública eficientemente, superando los problemas que actualmente afectan a las obras públicas, tales como la deficiente elaboración de los expedientes técnicos, las controversias entre el contratista y la Entidad, las interferencias y la falta de saneamiento del terreno, entre otros.

Bajo esta normativa, actualmente se ha creado, mediante Decreto Supremo 011-2020-MINEDU, el Proyecto Especial de Inversión Pública "Escuelas Bicentenario", que tiene por objeto la ejecución de una Cartera de Inversiones constituida por 75 proyectos de inversión de las Instituciones Educativas de Lima Metropolitana y de las Instituciones Educativas Emblemáticas ubicadas en 8 departamentos y la Provincia Constitucional del Callao.

\section{El Modelo de Ejecución de Inversiones Públicas}

EI DU 021-2020 no solo regula la creación y funcionamiento de los PEIP, sino también el Modelo de Ejecución de Inversiones Públicas que será utilizado por estos proyectos especiales. Este modelo ha sido estructurado, en principio, sobre la base de la experiencia de los Juegos Panamericanos, así como las mejores prácticas internacionales en gestión de proyectos.

De acuerdo con el artículo $10 \mathrm{del}$ Reglamento del DU 021-2020, el Modelo de Ejecución de Inversiones Públicas es "la agrupación de procesos, procedimientos 
e instrumentos metodológicos de un conjunto de buenas prácticas guiadas por altos estándares internacionales para la ejecución efectiva de las inversiones públicas; para lo cual brinda facilidades para su revisión y desarrollo, que aseguren la ejecución de las inversiones, a través del cumplimiento de su cronograma, costos, alcance y calidad establecida".

El artículo 11 del referido Reglamento regula las herramientas y facilidades comprendidas en este modelo, entre las que se encuentran la Junta de Cambios, la asistencia técnica para la gestión y ejecución de las inversiones, la Metodología colaborativa de modelamiento digital de información para la construcción (BIM), los contratos estandarizados, entre otros.

Estas herramientas se han venido empleando en proyectos de inversión pública, sobre todo, bajo el marco de contratos entre Estados, y algunas se han regulado en recientes normas, por lo que es necesario conocer sus características, como punto de partida para discutir la pertinencia de incluir su regulación en las contrataciones del Estado o para mejorarla.

\section{La Oficina de PMO y la Asistencia técnica para la gestión y ejecución de las inversiones}

\subsection{La Oficina de Gestión de Proyectos \\ El PMI señala que el PMO es:}

Una estructura de gestión que estandariza los procesos de gobierno, relacionados con el proyecto y hace más fácil compartir recursos, metodologías, herramientas y técnicas. Las responsabilidades de una PMO pueden abarcar desde el suministro de funciones de soporte para la dirección de proyectos hasta la responsabilidad de la propia dirección de uno o más proyectos (2013, p. 11).

Por su parte, el Plan Nacional de Infraestructura y Competitividad (PNIC) ha señalado:

Al no haber un claro lineamiento y una responsabilidad debidamente definida dentro de los ministerios, la tramitología interna genera demoras en la toma de decisiones. Por otro lado, por la envergadura o complejidad técnica de algunos proyectos, existe temor en los funcionarios por la falta de capacidades, lo que afecta el cumplimiento de los cronogramas y de los planes de inversión. La implementación de PMO surge como una necesidad (2019, p. 77).

Por ello, el Plan Nacional de Competitividad y Productividad, aprobado mediante Decreto Supremo 237-2019-EF, ha establecido como una de las medidas para dotar al país de infraestructura económica y social de calidad la implementación de las PMO. En dicho Plan se señala que esta medida propone incorporar en el Sistema Nacional de Abastecimiento la contratación de asistencia técnica de empresas especializadas en gerencia de proyectos para facilitar la mejora de las inversiones, el desarrollo de capacidades locales y la adopción de mejores prácticas de gestión mediante $\mathrm{PMO}$.

Como puede notarse, actualmente el Gobierno viene apostando por la implementación de la Oficina de Gestión de Proyectos (PMO) para la gestión de los proyectos públicos. Asimismo, en tanto se generen experiencias y capacidades en el sector público para implementar una $\mathrm{PMO}$ con el propio personal de la Entidad, se considera necesario contar con un servicio especializado de asistencia técnica en la ejecución de inversiones.

Esta apuesta por las PMO permitirá incrementar la eficiencia en la ejecución de los proyectos, profesionalizando la gestión de los mismos, con un seguimiento y medición constante de los riesgos, costos, cambios, entre otros aspectos vitales del proyecto. En suma, de cara a la constante crítica que se realiza a las obras públicas, se evitarán las paralizaciones, sobrecostos y otras patologías. Esto, claro está, redundará en una mejor y más oportuna atención de las necesidades públicas que subyacen a toda contratación pública.

En la línea de lo expuesto, el Reglamento del DU 021-2020 recoge esta tendencia, estableciendo como uno de los órganos que componen al PEIP a la Oficina de Gestión de Proyectos, siendo esta la oficina responsable de planificar, organizar y facilitar la implementación del modelo de ejecución de inversiones públicas en el proyecto de inversión o Cartera de Inversiones, de acuerdo al Plan de Ejecución del PEIP.

Entre las funciones de esta oficina se encuentra el diseño e implementación de procedimientos e instrumentos para la gestión integrada del PEIP; proponer el Plan de Ejecución del PEIP; establecer cronogramas para las distintas áreas de trabajo y monitorear su progreso y evaluación para el cumplimiento de los objetivos del PEIP; efectuar el seguimiento de los costos y del presupuesto del proyecto de inversión o cartera de inversiones; implementar y gestionar el Control Integrado de Cambios; gestionar los riesgos que afectan el proyecto; entre otras. 
Los proyectos especiales de inversión pública y el modelo de ejecución de inversiones públicas: revisión de las herramientas que pueden emplearse para mejorar las contrataciones del Estado

Special public investment projects and the public investment execution model: review of the tools that can be used to improve government contracting

Asimismo, de acuerdo con los Lineamientos Operativos para la Implementación del Modelo de Ejecución de Inversiones Públicas a través de Proyectos Especiales de Inversión Pública, aprobados mediante Resolución Directoral 009-2020-EF/63.01 (en adelante, los "Lineamientos de los PEIP"), la PMO aborda diferentes líneas de acción, entre las que se encuentran los cambios, riesgos, costos, contratos, estrategia BIM, adquisiciones, planeamiento, control documental, entre otras.

Además, señalan que la Oficina de Gestión de Proyectos tiene como objetivo establecerse como el punto de consulta y coordinación dentro del PEIP, al seguir desde el inicio el desarrollo de los proyectos de inversión a cargo del PEIP y ser una fuente de información para la gestión de proyectos.

De esta manera, la Oficina de Gestión de Proyectos tiene un rol transversal que abarca los diferentes procesos del PEIP, brindando soporte, lineamientos e información necesaria a todas las demás áreas del PEIP para la correcta ejecución de los proyectos de inversión pública y el funcionamiento eficiente del propio PEIP. rol:

En esta línea, Valdés señala que la PMO cumple un doble

Un rol normativo, que ayude a contar con un orden mínimo, que permita a la organización saber que está pasando con los diversos proyectos ejecutados concurrentemente y las relaciones de dependencia que pudieran existir entre cada uno de ellos; y un rol de servicio, que permita que el personal de esta entidad acompañe a los gerentes de proyecto en el desarrollo de sus funciones, compartiendo con ellos experiencias, consejos y buenas prácticas, así como el sentido de anticipación en la identificación de riesgos y soporte en la resolución de problemas y conflictos y en el uso adecuado de la metodología recomendando la "dosis" necesaria según las características del proyecto (2008).

Conforme a lo expuesto, considero bastante acertada la tendencia del Gobierno por insertar a las PMO en los proyectos de inversión pública, pues ello permitirá que los riesgos y cronogramas de los proyectos se encuentren debidamente monitoreados, permitiendo la respuesta oportuna de las áreas involucradas en cada caso, una gestión eficiente de los cambios del proyecto, que la Entidad a cargo tenga una estructura adecuada para ejecutar el proyecto, que se cuenten con documentos estándares que permitan la fluidez de las comunicaciones y aprobaciones; entre otros múltiples factores que aseguren un mayor control de la consecución de los objetivos del proyecto y que posibiliten la adopción eficiente de decisiones ante eventualidades que afecten los mismos.

De esta manera, considero beneficioso no solo apostar por regular las PMO en normas especiales y la contratación de servicio de asistencia técnica especializada, sino prever esta figura dentro de la normativa de contratación pública, así como invertir en la capacitación masiva de funcionarios públicos para que se integren a estas oficinas.

\subsection{El Equipo de Asistencia Técnica en Gestión de Inversiones}

Si bien la implementación de las PMO en los proyectos públicos resulta beneficiosa, el PNIC reconoce que aún no se cuenta con capacidad en las Entidades para llevarla a cabo, por lo que establece lo siguiente: "para abordar el problema de debilidad institucional para la gestión de proyectos, se plantea que los proyectos identificados en el PNIC podrán contar con un servicio de asistencia técnica especializada, tipo PMO, durante todo el desarrollo del proyecto" (2019, p. 74).

Es decir, en tanto se generen capacidades suficientes para que las Entidades organicen sus propias $\mathrm{PMO}$ con sus propios recursos, se plantea la alternativa de que estas contraten servicios de asesoría técnica de terceros que permitan cumplir con el rol de las PMO. Así, conforme a la Exposición de Motivos del Reglamento del DU 021-2020, el Equipo de Asistencia Técnica es un servicio que permite al PEIP contar con un suministro de especialistas con el fin de ir generando las capacidades que el PEIP y sus dependencias (especialmente la Oficina de Gestión de Proyectos) requieren para alcanzar niveles de calidad y oportunidad acordes a los estándares internacionales actuales.

En esta línea, el Reglamento del DU 021 2020 prevé que el PEIP contrata un Equipo de Asistencia Técnica Especializada en Gestión de Inversiones para que le brinde asistencia y acompañamiento técnico para el cumplimiento de sus funciones. Los servicios a requerir del Equipo de Asistencia Técnica varían dependiendo de cada PEIP y las necesidades particulares de los proyectos a su cargo.

Este Equipo de Asistencia Técnica propone la definición del alcance del proyecto de inversión o cartera de inversiones; elabora el Plan de Ejecución del PEIP y la Estrategia de Contratación; lleva a cabo el seguimiento de los contratos estándar, emite informes de recomendación de los proveedores adjudicados en procesos de contratación; entre otras funciones.

Como puede advertirse, en concordancia con lo previsto en el PNIC, la normativa ha previsto que los PEIP cuenten con una PMO 
interna, pero, además, con una asistencia técnica especializada externa que sirva de soporte y que ayude a que los funcionarios y servidores públicos encargados de la gestión del proyecto desarrollen las capacidades necesarias para ello.

Este esquema también se ha venido empleando en proyectos ejecutados con la asistencia técnica de Estados extranjeros, bajo la modalidad de contratación entre Estados. Así, por ejemplo, el Proyecto Especial para la Preparación y Desarrollo de los XVIII Juegos Panamericanos y Sextos Juegos Parapanamericanos del 2019 (ahora llamado "Proyecto Especial Legado de los Juegos Panamericanos”), en su Manual de Operaciones aprobado mediante Resolución Ministerial 1000-2017-MTC/01(2) contó con una Oficina de Gestión del Programa, que tuvo por función asesorar, monitorear y controlar el cumplimiento del Plan Maestro del proyecto.

A su vez, el Reino Unido, a través del contrato de Gobierno a Gobierno, brindó, entre otras funciones, asistencia a la Oficina de Gestión del Proyect ${ }^{(3)}$ mediante consultores que se encargaron de gestionar la planificación, el reporte, la supervisión y el control de todo el programa de Lima 2019, incluyendo, pero no limitado a la gestión de riesgo, de stakeholders, de cambios, del cronograma, el establecimiento de procesos estandarizados y la mejora de eficiencias. EI PNIC resalta este esquema empleado en los Juegos Panamericanos, atribuyéndole el éxito en el desarrollo de los juegos ${ }^{(4)}$.

Es preciso señalar que, de acuerdo con el Reglamento del DU 021-2020, para contratar el servicio de asistencia técnica, Ios PEIP pueden emplear un contrato estándar internacional, en cuyo caso se empleará el procedimiento de selección especial previsto en el artículo 14 dicha norma; o usar otro tipo de contratos, en cuyo caso se empleará el procedimiento previsto en el Decreto Supremo 236-2020-EF.

Sin perjuicio de esta estructura de asistencia técnica especializada prevista en el DU 021-2020, reitero que es importante que los funcionarios del Estado puedan aprender los estándares internacionales de gestión de proyectos, a fin de que integren las $\mathrm{PMO}$, sin recurrir o recurriendo de forma reducida a asesoría externa. Ello ayudará a incrementar la capacidad del Estado para gestionar proyectos públicos, que tanto se viene cuestionando actualmente y que sirve de fundamento para crear mecanismos poco regulados de contratación.

Actualmente, pese a la intención del Estado de promover la implementación de las PMO, a la fecha aún existe poco entendimiento respecto de los roles y funciones de esta figura. Algunos funcionarios ven a la PMO únicamente como un instrumento para realizar contrataciones más ágiles, mientras que otros lo ven como un vehículo para excluirse de la aplicación de la ley de contrataciones del Estado (mediante contratos de Gobierno a Gobierno), sin interiorizar sus grandes ventajas.

Por ello, a fin de que los funcionarios públicos obtengan capacidades en la implementación de las PMO, considero importante que se difunda de manera más amplia el know-how obtenido en la ejecución de los proyectos llevados a cabo mediante contratos entre Estados (Juegos Panamericanos, Aeropuerto Internacional de Chinchero, Hospitales del MINSA, entre otros). Esta difusión debe implicar compartir los retos afrontados, los errores, los aciertos, los costos, los documentos de gestión y reportes desarrollados, entre otros aspectos.

\section{Junta de Cambios}

El numeral 5.8 del artículo 5 del Reglamento del DU 021-2020 establece que la Junta de Cambios es un grupo integrado por el Director Ejecutivo, el responsable de la Oficina de Gestión de Proyectos, el responsable de la Oficina de Infraestructura, el responsable de presupuesto y otros funcionarios o servidores que el Director Ejecutivo determine; y tiene la función de revisar, evaluar, aprobar o rechazar los cambios propuestos por las áreas del PEIP con relación a la ejecución del proyecto de inversión o Cartera de Inversiones. El equipo de Asistencia Técnica Especializada en Gestión de Inversiones participa de las sesiones de la Junta de Cambios.

Además, el numeral 6.4 del artículo 6 de dicho Reglamento establece que la Junta de Control de Cambios tiene como responsabilidades:

- Revisar todas las solicitudes de cambio presentadas por las unidades funcionales

(2) Actualmente derogado.

(3) Acuerdo de Implementación 2.

(4) EI PNIC señala que "este éxito se debe, en gran medida, al enfoque de gerencia de proyectos de la unidad ejecutora y al hecho de que se contó con el apoyo de un Project Management Office (PMO) cuyo rol fue fundamental en dos aspectos: 1. Sistemas de información. 2. Apoyo técnico para la toma de decisiones" (2019, p. 77). 
Los proyectos especiales de inversión pública y el modelo de ejecución de inversiones públicas: revisión de las herramientas que pueden emplearse para mejorar las contrataciones del Estado

Special public investment projects and the public investment execution model: review of the tools that can be used to improve government contracting

que conforman el Proyecto Especial, las cuales deben encontrarse debidamente fundamentadas, incluyendo su evaluación de impacto.

- Aprobar o rechazar las solicitudes de cambio propuestas.

- Diferir la decisión sobre las solicitudes de cambios en los casos que lo considere pertinente.

- Colaborar en el proceso de gestión de cambios para asegurar la debida celeridad del proceso.

En la experiencia pública, podemos advertir que en el Proyecto Especial para la Preparación y Desarrollo de los XVIII Juegos Panamericanos y Sextos Juegos Parapanamericanos de Lima también se estableció una Junta de Cambios. En efecto, mediante Resolución Directoral Ejecutiva 019-2018MTC/PEJP-2019 se creó la "Junta de Control de Cambios" como una herramienta de gestión de dicho Proyecto Especial.

En dicha Resolución, que resulta ilustrativa, se indica que esta junta está integrada por los responsables de la Alta Dirección del Proyecto Especial, que realizarán la evaluación de la toma de decisiones sobre cualquier cambio que afectara la Línea de Base del Programa, lo que permitirá sustentar los cambios realizados, alinear los estimados de costos de los diseños, alinear los estimados de costos a las estrategias, establecer una nueva línea base para poder ejercer una mejor supervisión sobre la gestión mediante un proceso de control de cambios y la posterior propuesta al órgano competente para su aprobación. Asimismo, agrega que la Junta de Control de Cambios "busca deliberar y tomar decisiones a fin de implementar un proceso previo que otorgue transparencia ante cualquier propuesta de cambio en el alcance, cronograma y costo de los proyectos que desarrolla el Proyecto Especial"(5) (Resolución Directoral Ejecutiva 019-2018-MTC/PEJP-2019).

Precisado lo anterior, debe tenerse presente que la Junta de Cambios es parte del proceso de Control Integrado de Cambios que, conforme al PMBOK:

Implica revisar todas las solicitudes de cambio, aprobar y gestionar cambios a entregables, documentos del proyecto y al plan para la dirección del proyecto; y comunicar las decisiones. Este proceso revisa todas las solicitudes de cambio a documentos del proyecto, entregables o plan para la dirección del proyecto y determina la resolución de las solicitudes de cambio. El beneficio clave de este proceso es que permite que los cambios documentados dentro del proyecto sean considerados de una manera integrada y simultáneamente aborda el riesgo general del proyecto, el cual a menudo surge de cambios realizados sin tener en cuenta los objetivos o planes generales del proyecto (Project Management Institute, 2017, p. 113).
Por su parte, el literal f) del artículo 3, del Reglamento del DU 021-2020 define el Control Integrado de Cambios como el proceso "por el cual se identifican, documentan, aprueban o rechazan cualquiera de los cambios propuestos para la ejecución efectiva del proyecto de inversión o Cartera de Inversiones del PEIP. Forma parte de las funciones de la Oficina de Gestión de Proyectos".

\section{Añade el PMBOK que:}

Si fuera necesario, el proceso Realizar el Control Integrado de Cambios incorporará un comité de control de cambios (CCB), que es un grupo formalmente constituido responsable de revisar, evaluar, aprobar, aplazar o rechazar los cambios en el proyecto, así como de registrar y comunicar dichas decisiones (Project Management Institute, 2017, p. 115).

\section{Como señala Lledó:}

En aquellos casos que existe un Comité de cambios, cualquier implementación de cambio que vaya a modificar alguna línea base (alcance, tiempo, costo, calidad) debe ser aprobada previamente por este Comité. La única excepción sería en caso de fuerza mayor donde el DP puede realizar cambios de emergencia para mitigar riesgos (2017, p. 117).

En líneas generales, puede rescatarse que el empleo de la Junta de Cambios permite una evaluación y aprobación rápida de cualquier cambio que pueda afectar la ejecución del proyecto, asegurando la intervención oportuna de todos los actores responsables del mismo. Este mecanismo evita que un importante cambio tenga que pasar por la evaluación aislada de cada oficina del PEIP, con la emisión de los informes y otros documentos emitidos de forma independiente y que pueden ser contradictorios entre sí, generando retrocesos innecesarios.

Es común en la contratación pública nacional que los funcionarios no aprueben fácilmente los cambios propuestos a los proyectos, que se demoren en adoptar decisiones o que gasten valioso tiempo en discutir respecto de qué órgano debe asumir

(5) Actualmente, la Directiva 001-2021-MTC/34.01, aprobada mediante Resolución Directoral Ejecutiva 009-2021-MTC/34, del Proyecto Especial Legado Juegos Panamericanos y Parapanamericanos, que define a la Junta de Cambios como el "Equipo de Trabajo designado para deliberar los cambios propuestos que afecten la línea de base del alcance, cronograma y costos de las inversiones y actividades del portafolio del Proyecto Especial". 
la responsabilidad por las decisiones adoptadas. Cada órgano de la Entidad espera un pronunciamiento de otro órgano para respaldar su propia decisión. Este mecanismo poco colaborativo y desorganizado genera pérdida de recursos, así como conflictos entre las dependencias de la Entidad.

La Junta de Cambios permite que los representantes de todos los órganos que se ven involucrados en la evaluación de un cambio y la toma de una decisión realicen estas actividades de forma conjunta, de manera colaborativa y transparente, evitando la práctica de protegerse buscando el traslado de su responsabilidad a otros funcionarios. Es una forma eficiente de lograr consensos, compromisos y decisiones ágiles de los funcionarios pertinentes en beneficio del proyecto.

Esto es particularmente beneficioso cuando los cambios que se someten a consideración se encuentran referidos a la ejecución de un contrato de obra -por ejemplo, cambios de alcance-, pues permite que la decisión no se dilate, generando el derecho del contratista de reclamar las consecuencias legales de dicha demora (ampliaciones de plazo, reconocimiento de costos, daños, resolución, o cualquiera sea el mecanismo que aplique conforme al contrato).

Por ello, considero importante implementar debidamente las Juntas de Cambios en la estructura de las Entidades que ejecutan obras públicas, pues, como mencioné anteriormente, puede acelerar el actualmente lento proceso de toma de decisiones, articulando responsabilidades y permitiendo la mitigación oportuna de riesgos. Además, este mecanismo promoverá la colaboración interna de la Entidad, reduciendo las fricciones en las relaciones de los funcionarios, generando conciencia y compromiso con la consecución de los fines del proyecto.

\section{Estrategia de Contratación}

\subsection{La Estrategia de Contratación}

De acuerdo con el literal I) del artículo 3 del Reglamento del DU 021-2020, la Estrategia de Contratación es el conjunto de procesos, factores y criterios que determinan las acciones a seguir en la contratación y selección de bienes, servicios y/o ejecución de obras necesarias para alcanzar los diversos objetivos del proyecto de inversión o Cartera de Inversiones del PEIP.

La Estrategia de Contratación establece los sistemas de entrega a seguir previa evaluación comparativa, los Contratos estandarizados a emplear, la identificación de aquellos factores que determinan la ejecución del proyecto-drivers; así como determina las alternativas de empaquetamiento y procesos de control para desarrollar y administrar los acuerdos para la ejecución efectiva de los contratos, entre otros aspectos, con el fin de buscar la mejor combinación costobeneficio para lograr los objetivos del proyecto de inversión o Cartera de Inversiones. La estrategia de contratación es elaborada por el Equipo de Asistencia Técnica Especializada en Gestión de Inversiones y es aprobada por el Director Ejecutivo del PEIP.

De acuerdo con los Lineamientos, la estrategia de contratación tiene por objeto:

- Alinear las contrataciones con los objetivos del proyecto o paquetes de proyectos, los riesgos, consideraciones, limitaciones y el estado del mercado.

- Seleccionar los contratos estándares más apropiados para cada caso.

- Revisar los objetos de las inversiones y proponer estrategias de empaquetamientos.

- Revisar paquetes de contratación, asegurando que los alcances estén robustamente definidos y alineados con la estrategia de contratación.

- Definir los pasos y criterios de evaluación durante todo el proceso de contratación, que llevarán, finalmente, a la designación de un contratista o contratistas, según el caso.

Esta herramienta evoca a lo que en los últimos Contratos de Gobierno a Gobierno se ha denominado políticas de procura o estrategias de procura. Así, por ejemplo, en la Cláusula Segunda del Contrato de Gobierno celebrado entre el Ministerio de Salud y el Estado de Francia para la asistencia técnica en la ejecución de los hospitales Sergio Bernales y Lorena, se previó que las Políticas de Procura son los procedimientos, términos y condiciones que deberá aplicar el Estado de Francia para el desarrollo de la Fase de Procura Internacional de dicho Proyecto, los que deberán estar de acuerdo con los principios de transparencia, equidad y competencia.

A su vez, en el alcance final actualizado de dicho contrato se previó que en la fase de procura internacional del proyecto se espera que la PMO (organizada por Francia) evalúe e implemente los instrumentos contractuales (contratos de elaboración de expediente técnico, de construcción de obra, equipamiento integral y puesta en marcha) y la estrategia de procura más adecuada 
Los proyectos especiales de inversión pública y el modelo de ejecución de inversiones públicas: revisión de las herramientas que pueden emplearse para mejorar las contrataciones del Estado

Special public investment projects and the public investment execution model: review of the tools that can be used to improve government contracting

para la ejecución del proyecto; asimismo que se encargue de la organización, gestión y ejecución del proceso de procura internacional bajo altos estándares de transparencia e integridad.

Como vemos, en los contratos entre Estados forma parte de las funciones de los Estados extranjeros que brindan asistencia técnica en gestión de inversiones, de manera previa a lanzar cualquier convocatoria de proceso de procura internacional, la definición de una estrategia de contratación que no solo determine el tipo de contrato a emplearse, sino el Sistema de Entrega de Proyecto más eficiente para alcanzar la finalidad del mismo, la forma de acceder al mercado, los requisitos exigibles a los participantes en los procesos de procura, la estrategia de empaquetamiento, entre otros aspectos.

Esta herramienta es muy importante y es un aspecto clave a implementar en la contratación pública nacional, donde es dejada de lado. Cuando se contrata en el sector público no basta con que la decisión del servidor se base en criterios legales y cumplimiento de formalidades, sino en una adecuada planificación y estrategias eficientes para que la contratación se encuentre alineada con los objetivos del proyecto y que sirva para generar sinergias y eficiencias.

Normalmente, bajo la normativa de contrataciones del Estado, el servidor público solo se centra en elegir el procedimiento de selección conforme a los parámetros normativos y a seguir los pasos y formalidades de la norma, llenando las bases estándares conforme a las instrucciones que vienen prefijadas por el Organismo Supervisor de las Contrataciones del Estado (OSCE).

En cambio, en los PEIP, que tienen una mayor flexibilidad y discrecionalidad, se deberá elaborar, luego de un importante análisis, una estrategia de contratación (sistema de entrega de proyecto, definición de prioridades, forma de acercarse al mercado, tipo de contrato a emplearse, empaquetamiento, etc.) conforme a los drivers identificados, la naturaleza y características particulares del proyecto de inversión y del PEIP, las capacidades del personal del PEIP, las características del mercado objetivo, entre otros aspectos.

Recientemente se viene poniendo mucho énfasis en el empleo de contratos estándares internacionales, atribuyéndoles a estos los resultados obtenidos en los proyectos en los que el Estado peruano ha empleado contratos entre Estados. Sin embargo, la elección de un contrato estándar no se realiza de manera aislada por el simple hecho de que este haya sido beneficioso en otros proyectos, sino que obedece a un análisis a fondo de diferentes elementos del proyecto.

El propietario -en este caso, una Entidad o PEIP- debe conocer cómo quiere que se ejecute el proyecto, qué riesgos desea asumir, qué experiencia previa tiene, con cuántos recursos cuenta, qué tipos de contratos conoce y puede ejecutar eficientemente, con qué personal cuenta, el tiempo y el presupuesto para ejecutar el proyecto, la disponibilidad de los fondos, la capacidad de gestión contractual que tiene, entre otros muchos aspectos, antes de decidir el tipo de contrato que va a emplear.

Todos estos elementos deben ser analizados con ocasión de la estrategia de contratación, por lo que esta herramienta resulta más amplia e importante que la sola elección de un contrato estándar internacional. La consideración de estas interrogantes puede llevar a determinar que, aun cuando un contrato estándar internacional haya sido empleado con éxito en otros proyectos similares, finalmente no sea el mejor para la Entidad, pues no tendrá la capacidad para ejecutarlo sin contratiempos ni controversias, o requerirá invertir demasiados recursos en asesoría externa para entender el contrato que ha celebrado.

Así, de desarrollarse con la importancia debida en la normativa de contrataciones del Estado la estrategia de contratación, esta servirá para marcar el norte de las Entidades respecto de qué contrato emplear, cómo manejar los riesgos, qué paquetes de contratación considerar, cuándo lanzar sus procesos de contratación y bajo qué modalidades, sin empelar encargos $u$ otras herramientas especiales, entre otras consideraciones.

\subsection{El Sistema de entrega de proyectos} Como puede advertirse, uno de los elementos esenciales de la Estrategia de Contratación es la determinación del Sistema de Entrega de Proyectos (Project Delivery System o PDS), antes de la elección del modelo de contrato más conveniente para el proyecto.

De acuerdo con la CMAA:

Cada propietario responsable por la implementación de un proyecto de construcción debe tomar una temprana e importante decisión sobre el método mediante el cual el proyecto será diseñado y construido -el sistema de entrega de proyecto [proyect delivery system]. Esta decisión se ha vuelto más difícil en los años recientes dados los varios sistemas alternativos que han sido desarrollados para sobrellevar las potenciales dificultades del sistema tradicional. Los métodos que han 
ganado popularidad incluyen el construction management at risk, multiple prime contracting, design-build, y más reciente, el Integrated Project Delivery (2012, p. 10).

Por su parte, García señala que:

El Project Delivery System es el método mediante el cual se define la estructura de las relaciones entre las partes intervinientes en la ejecución del proyecto de construcción, sus funciones y la secuencia general de actividades (Moore, 2000). Dicha definición estará a cargo exclusivamente del propietario a base de sus intereses y requerimientos. De esta manera, la decisión de las labores de diseño y construcción recaerán en un solo sujeto mediante un contrato o en dos sujetos con contratos independientes estará en manos del propietario (2020, p. 110).

\section{Como señala Klee:}

Un proyecto de construcción es un sistema único de procesos que involucra varios participantes con diferentes obligaciones condicionadas por varios factores, amenazas y riesgos vinculados. Con ello en mente, el sistema de entrega correcto (forma de administración y organización del proyecto de construcción) debe ser seleccionado, correspondiendo al propietario la elección de esta decisión (2015, p. 53).

En efecto, corresponde al propietario determinar el PDS, que es la columna vertebral del diseño del contrato a celebrarse. EI PDS define qué obligaciones serán asumidas por cada parte, cómo se distribuirán los riesgos, cuántas relaciones contractuales se involucrarán, en qué fases intervendrá cada actor, el límite de las responsabilidades de las partes, una correcta estructura de incentivos, entre otros. Solo conociendo estos aspectos se podrá elegir algún modelo de contrato que calce con los requerimientos definidos por el propietario.

Existen diversos sistemas de entrega de proyectos. La clasificación puede variar según cada autor o cada jurisdicción en que nos encontremos, por lo que no es propósito de este breve artículo ahondar en cada PDS. Solo me referiré de manera general a los principales PDS y, en particular a la Gerencia de Proyectos, que viene siendo empleada en importantes proyectos como los Juegos Panamericanos y la Reconstrucción con Cambios, la cual no cuenta con reconocimiento en nuestra normativa de contrataciones del Estado.

\subsubsection{El método tradicional o DBB (Design - Bid - Build)} De acuerdo con Franco:

En el método tradicional se separa la construcción del diseño. Se contrata un contratista para construir lo que los ingenieros y arquitectos han especificado. En este esquema el contratista suele no asumir responsabilidad por la exactitud del diseño, lo cual puede generar cierta dificultad al determinar la responsabilidad por defectos o si la construcción no alcanza los objetivos esperados por el propietario. La menor responsabilidad del constructor suele implicar también un menor precio en comparación con un contrato de diseño y construcción (2015, p. 12).

El método tradicional es el que comúnmente emplea nuestra normativa de contrataciones del Estado para la ejecución de obras públicas. Su denominación (DBB) viene dada por el hecho de que el propietario primero contrata el diseño del proyecto, luego se encargará de seleccionar al contratista que finalmente se encargará de ejecutar el proyecto conforme al diseño que se le proporcione.

En este PDS el propietario tiene dos relaciones contractuales principales: una primera con un diseñador o proyectista, y una segunda relación con el ejecutor de la obra, quien tendrá que ejecutar el proyecto conforme a lo definido con el proyectista.

Esto implica que el propietario deba administrar al menos dos contratos, siendo que ambos pueden generar controversias que deriven en algún mecanismo como el arbitraje. Ello, sumado a otros contratos que puedan verse vinculados con estos, como la supervisión, puede generar que el propietario emplee mayores esfuerzos en la administración contractual.

En este PDS el propietario deberá articular de la mejor manera estas dos relaciones contractuales, pues cualquier deficiencia en el trabajo del proyectista podrá generar una controversia o el reconocimiento de un derecho en favor del ejecutor. Además, debería cuidar que el proyectista preste asistencia o algún nivel de colaboración durante la ejecución de la obra, a fin de disipar cualquier duda o analizar cualquier variación a su proyecto que levante el ejecutor.

La ventaja, en contraposición, es que el propietario podrá evaluar previamente el diseño y aprobarlo antes de elegir al contratista ejecutor. Asimismo, teniendo los cuidados necesarios, contará durante la ejecución con el soporte del proyectista para superar cualquier deficiencia del diseño o absolver cualquier duda del constructor.

\subsubsection{Diseño y Construcción}

En este PDS el empleador celebra un único contrato en el cual el contratista asume la responsabilidad tanto por el diseño del proyecto conforme a los requerimientos definidos por el propietario y la ejecución del proyecto.

En este caso habrá un único contrato en el que se concentran las responsabilidades 
Los proyectos especiales de inversión pública y el modelo de ejecución de inversiones públicas: revisión de las herramientas que pueden emplearse para mejorar las contrataciones del Estado

Special public investment projects and the public investment execution model: review of the tools that can be used to improve government contracting

de un proyectista y un ejecutor, por lo que el propietario deberá gestionar una única relación contractual. No obstante, esto implica que la Entidad no cuente con un proyectista que pueda acompañar la ejecución de la obra, asesorando respecto del diseño y evalúe los cambios propuestos por el contratista.

De otro lado, toda vez que el contratista será responsable por la ejecución del diseño, este deberá asumir durante la ejecución de la obra los errores de su propio diseño. Su responsabilidad es mayor y, por tanto, el precio que cobra también es mayor. Dependiendo de la complejidad del proyecto, elegir este PDS puede reducir la cantidad de contratistas disponibles en el mercado, en comparación con el método tradicional.

El artículo 36 del Reglamento de la Ley de Contrataciones del Estado, aprobado mediante Decreto Supremo 344-2018-EF, recoge las modalidades de contratación. Tanto la modalidad de llave en mano para obras que incluye la elaboración del expediente técnico como el concurso oferta corresponden al PDS de Diseño y Construcción.

Además, el Título VIII de dicho reglamento regula la ejecución de obras que incluyen diseño y construcción. Así, el artículo 213 establece que, para usar este PDS, resulta necesario que el expediente de contratación contenga los requisitos de la Entidad, el Estudio básico de ingeniería, la asignación de riesgos y la ficha técnica o el estudio de preinversión que sustentó la declaratoria de viabilidad parta proyectos de inversión o la información del registro de las inversiones de ampliación marginal, rehabilitación y de optimización, según corresponda.

Además, el artículo 212 del referido reglamento establece que el Organismo Supervisor de las contrataciones del Estado (OSCE) regulará las disposiciones complementarias para la aplicación de este PDS, lo cual puede incluir la posibilidad de emplear contratos estándares internacionales. No obstante, a la fecha, aún no se ha emitido esta regulación complementaria.

\subsubsection{Gerencia de Proyectos}

EI PDS de gerencia de proyectos implica que el contratista designado, antes que un constructor, sea un gestor del proyecto. Su obligación principal es administrar la obra para que esta se cumpla conforme a las condiciones de tiempo, calidad y presupuesto esperadas. Este PDS tiene dos modalidades, la Gerencia de Proyectos como Agencia y la Gerencia de Proyectos al Riesgo.

En la Gerencia de Proyectos como Agencia el contratista brindar asesoría necesaria al propietario (Entidad, en el sector público) para que el proyecto se ejecute conforme a lo esperado. En este caso el contratista no asume una obligación de resultados, pues solo debe brindar sus servicios de manera diligente, conforme a su experiencia y conocimientos, para que la obra se ejecute eficientemente.

De esta manera, en principio, para evitar que se le impute responsabilidad contractual, el contratista deberá demostrar que en la emisión de sus recomendaciones actuó diligentemente, conforme a sus conocimientos especializados, aun cuando el proyecto no se haya ejecutado dentro del alcance, precio y tiempo previstos.

\section{Como señalan Block y Curran:}

Como un asesor, el contratista administrador es, esencialmente, responsable solo por sus propios actos de negligencia o incumplimiento contractual. No se considera que actúe "al riesgo" respecto del costo, tiempo o calidad del desempeño de los contratistas ejecutores". Así, por ejemplo, estos autores agregan que "el contratista puede, como parte de su contrato con el propietario, realizar estimados del costo de las obras, pero estos estimados normalmente no están garantizados (2010, p. 1).

En esta modalidad de agencia nos encontramos ante un contrato de servicios y no de construcción. Es el propietario quien celebra por cuenta propia los contratos con el proyectista y el ejecutor de la obra. El contratista agente no forma parte de estos contratos ni es responsable por cualquier incumplimiento de estos contratistas.

En cambio, bajo la modalidad de gerencia al riesgo, el contratista es el obligado principal frente al propietario, no es solamente un consultor. En este caso, el contratista asume una obligación de resultados: que la obra se ejecute eficientemente. El contratista sigue teniendo como prestación principal ser un gestor del proyecto, pero en este caso asume el riesgo y la responsabilidad porque el proyecto se ejecute eficientemente conforme a lo definido en el alcance del mismo.

Toda vez que el gerente de proyecto al riesgo es el contratista principal que asume la responsabilidad total del proyecto, pero no tiene por obligación principal la de ser ejecutor de la obra, en la práctica, asume el rol de ser un administrador de subcontratos. Serán diferentes subcontratistas los que se encarguen de ejecutar el proyecto. El gerente 
de proyecto al riesgo deberá encargarse de que todos estos subcontratistas ejecuten eficientemente sus obligaciones, asumiendo frente al empleador la responsabilidad por cualquier incumplimiento de estos subcontratistas que afecte el proyecto como si lo hubiera ejecutado él mismo.

Puede notarse que, en el caso de la gerencia de proyectos como agencia, es la Entidad la que celebra directamente y asume la responsabilidad con los contratistas que se encarguen de diseñar y ejecutar la obra. De esta manera, la Entidad deberá administrar diferentes contratos (incluido el de su agente). Sin embargo, este entramado de relaciones contractuales se simplifica en la modalidad del contratista administrador al riesgo, pues la Entidad tendrá solo un contrato con el contratista administrador, y será este el que celebre subcontratos con los diferentes ejecutores del proyecto y asuma la responsabilidad por el cumplimiento de las obligaciones de estos.

El sistema de entrega de proyectos de gerencia al riesgo ha sido el empleado en la ejecución de los Juegos Panamericanos y actualmente en las obras de la reconstrucción con cambios, mediante el empleo de la modalidad de contratación entre Estados y el uso de los contratos NEC ECC Opción F.

Así, por ejemplo, en las cláusulas de los Contratos NEC ECC Opción F celebrados para las diferentes obras de la Reconstrucción con Cambios se ha agregado una cláusula que define el sistema de entrega del proyecto que señala lo siguiente:

El Sistema de Entrega de Proyecto (Project Delivery System) de este Contrato consiste en una Gerencia de Proyecto al Riesgo (Management Contracting at Risk) y la Modalidad NEC 3 Opción $\mathrm{F}$ donde el Contratista asume el riesgo de ejecución, resultado y plazo a los Precios y formas de pago establecidas en el Contrato. El Contratista es un gestor y se espera que subcontrate todos los trabajos a excepción de aquellos paquetes que ejecute él mismo, según se haya establecido en la Ficha de Datos del Contrato o sea aceptado por el Gerente del Proyecto durante la ejecución del Contrato. El Contratante no tiene ninguna relación o responsabilidad con los subcontratistas, todo conflicto o controversia que surja entre el Contratista y sus Subcontratistas no deben afectar la ejecución de los trabajos por el Contratista.

Este sistema no se encuentra recogido en nuestra normativa de contrataciones del Estado, pero su uso ha permitido que se ejecuten importantes proyectos de infraestructura en el Perú, por lo que considero conveniente estudiar la posibilidad de implementar este PDS en una próxima modificación normativa. Con el avance de la ejecución de los contratos de la Autoridad de la Reconstrucción con Cambios que emplean este PDS y la experiencia recogida en los Juegos Panamericanos, se contará con experiencias que sirvan como base para evaluar la conveniencia de regular este PDS y las condiciones necesarias para ello.

De manera preliminar, se puede señalar que la Gerencia de Proyectos al Riesgo resulta conveniente cuando la
Entidad no tiene experiencia ni capacidad suficiente para ejecutar el proyecto; cuando se cuente con poco margen de tiempo para ejecutar el proyecto (driver plazo), por lo que es necesario contar con un gestor que administre correctamente el proyecto para que se cumpla de acuerdo a lo requerido por el cliente; y cuando el proyecto revista una alta complejidad que dificulte su correcta administración (por ejemplo, que se prevea la participación de diferentes empresas constructoras, varios paquetes de subcontratación).

\subsubsection{Sistemas colaborativos}

El reporte de Michael Latham de 1994 reconocía en la industria de la construcción del Reino Unido que las más efectivos modelos de contratos deben incluir "un deber específico de todas las partes para cooperar entre estas y con sus subcontratistas, especialistas y proveedores, en una atmósfera de cooperación mutua" (1994, p. 37).

Se reconoce que la colaboración, la confianza mutua, evitar el conflicto, la búsqueda de soluciones que prioricen el proyecto en beneficio las partes involucradas genera valor en los proyectos de construcción y reducen los costos de transacción.

Sin embargo, en la obra pública nacional, que está sujeta a varias vicisitudes, la tendencia es que no exista confianza entre las partes. La obra pública nacional es conflictiva. Las partes, lejos de colaborar, son propensas a generar controversias, ocultar información y actuar de forma oportunista.

Es importante impulsar la colaboración entre las partes en los contratos de obra. Para ello no existe un único modelo o estándar de colaboración. Por el contrario, existen diferentes herramientas y metodologías de trabajo que promueven la colaboración entre las partes. Estas pueden ir desde un debe general de buena fe, propio de nuestro sistema legal, a esquemas sofisticados de trabajo conjunto entre las partes en donde se comparten riesgos y beneficios. Los mecanismos de colaboración son variados y no son taxativos, pero, por encima de cualquier provisión contractual, la actitud adoptada por las partes es primordial. 
Los proyectos especiales de inversión pública y el modelo de ejecución de inversiones públicas: revisión de las herramientas que pueden emplearse para mejorar las contrataciones del Estado

Special public investment projects and the public investment execution model: review of the tools that can be used to improve government contracting

Aunado a un cambio de modelo contractual o cambio normativo, debe estar el esfuerzo por los diferentes agentes del mercado para cooperar y variar el paradigma confrontacional que predomina en la obra pública nacional.

Mucho se habla actualmente de los "contratos colaborativos", usando este término incluso como sinónimo de contrato estándar internacional. Pero no todos los contratos estándares son colaborativos. Existen contratos con diferentes niveles de colaboración, llegando a modelos contractuales reconocidos como propiamente colaborativos, que comprenden complejas estructuras de trabajo, adopción de decisiones y asunción de riesgos, beneficios y pérdidas de manera conjunta ${ }^{(6)}$.

Conforme a ello, Franco señala que:

La propuesta última del enfoque colaborativo es eliminar la fragmentación de los equipos que participan en un proyecto tanto como sea posible. Los esquemas más ambiciosos de colaboración plantean la estructura organizativa del proyecto de manera radicalmente distinta a lo que estamos acostumbrados. De hecho, la aplicación del enfoque colaborativo a cabalidad lleva a crear una organización virtual entre todos los equipos de proyecto, lo cual se distingue por ser una modalidad de contratación distinta a las otras usadas regularmente, como el método tradicional que separa el diseño y la construcción, la modalidad de diseño y construcción y la modalidad de administración o gerenciamiento (2020a, p. 184).

De acuerdo con el reporte Mckinsey, una de las claves para incrementar la productividad en el sector de la construcción se encuentra la colaboración. De acuerdo con este informe:

Para permitir el éxito en cualquier tipo de acuerdo contractual, es esencial establecer un ambiente colaborativo y de confianza entre las partes. Esto puede ser logrado a través de una definición temprana y alineamiento al alcance del proyecto, una mejorada gestión de procesos y el incremento de la transparencia durante la vida del proyecto (2017, p. 71).

Además, añade este informe que resulta importante invertir tiempo y recursos para desarrollar el alcance del proyecto, dividiéndolo en paquetes de proyecto administrables; considerar prioritaria la integración y la administración de interfases, para lo cual es necesario que se realice la integración entre los diferentes actores del proyecto; asegurarse de que todos los agentes del proyecto se encuentren trabajando sobre una misma información integrada; aprendizaje y conocimiento mutuo.

En este informe también se señala que, para que la estructura del contrato promueva la colaboración, resulta necesario que los propietarios incluyan programas de incentivos en sus contratos o usen contratos más sofisticados que eviten el ambiente hostil propio del contrato de construcción, para ello.
Dentro de los PDS colaborativos, por ejemplo, se encuentra el Integrated Project Delivey System. De conformidad con Spittler y Nelson (2011), este Sistema:

Ofrece resolver los defectos de los actuales PDS, mediante el uso de un proceso de diseño colaborativo y un entorno de construcción. Cada vez más propietarios están considerando al IPD como un PDS alternativo porque este propone una reducción de costos, mayor velocidad, una mayor responsabilidad por el desempeño y la sostenibilidad del proyecto. El eje alrededor del que gira el IPD son los procesos colaborativos. EI IPD requiere que todos los participantes del proyecto colaboren durante la vida del proyecto para el beneficio del propio proyecto, a través de los retos e incertidumbres que suelen atravesar los procesos de construcción y diseño.

Sin ánimo de ahondar en los PDS colaborativo, tema amplio y en constante mejora y desarrollo, considero importante resaltar la necesidad de hacer esfuerzos normativos y culturales para promover el trabajo colaborativo, alineando los intereses de las partes que normalmente suelen estar contrapuestos.

Definitivamente, esta cultura colaborativa debe ir más allá que un deber genérico de colaboración o el reconocimiento del principio de buena fe. La normativa de obras debería recoger expresamente el enfoque colaborativo en cada uno de sus instituciones, dejando de incentivar el oportunismo y el conflicto.

Es importante destacar que, mediante Resolución Ministerial 141-2021-EF/54, el Ministerio de Economía y Finanzas pre publicó el Proyecto de nueva Ley de Contrataciones del Estado, en cuyo artículo 2 se recoge expresamente el Principio de Colaboración, según el cual "el actuar de todo aquel que participe en el proceso de contratación debe procurar (...) la colaboración oportuna y eficaz para el logro de la finalidad que se persigue".

Este principio no resulta suficiente para incentivar una actuación colaborativa entre las partes de un contrato de obra pública, por lo que se requiere que este sea acompañado

(6) Por ejemplo, contratos FAC-1. 
de disposiciones que realmente estimulen esta actuación en beneficio del proyecto, de manera tal que ambas partes perciban que están obteniendo una mejoría.

En este contexto, se han dado pasos importantes hacia la colaboración con la adopción del Plan BIM Nacional y la promoción de la Junta de Resolución de Disputas, pero existen otras herramientas que podrían ser estudiadas en la normativa de contrataciones del Estado, como el involucramiento temprano del contratista, la implementación de procedimientos que fomenten la colaboración de los proveedores como el diálogo competitivo, el reconocimiento de incentivos antes que castigos, la correcta asignación y administración de los riesgos, que podrían fomentar la colaboración.

\section{Contratos Estándares Internacionales}

De acuerdo con la primera disposición complementaria final del Decreto de Urgencia, los contratos estandarizados son: Formas contractuales estándar, guías, y otra documentación de uso general en el mercado de la construcción que utilizan terminología y condiciones expresadas de una manera simple y clara, las cuales son creadas y actualizadas por organizaciones internacionales especializadas, con la finalidad de que los modelos contractuales se encuentren acordes a las necesidades de la industria de la construcción.

Según los Lineamientos del Decreto de Urgencia, la aplicación de dichos contratos estandarizados en un PEIP permite contar con instrumentos técnicos y legales adecuados a la terminología de construcción y ejecución de inversiones bajo estándares de buenas prácticas internacionales. En ese sentido, dichos contratos consideran aspectos, características y terminología propia de una relación contractual para la construcción y ejecución de inversiones de niveles internacionales.

Además, señalan que estos contratos utilizan la terminología y condiciones expresadas de una manera simple y clara para que los modelos contractuales, el mecanismo de resolución de disputas, las responsabilidades y gestión de riesgos, entre otros necesarios para el ámbito de la construcción tengan un fácil entendimiento y aplicación en función al logro de objetivos.

Ahora bien, la Exposición de Motivos del DU 021-2020 recoge mis opiniones en un trabajo anterior, señalando que:

En el ámbito de la construcción se han desarrollado diferentes modelos de contratos internacionales que simplifican la coordinación de las acciones entre las partes involucradas, disminuyendo significativamente la pérdida de recursos que implica la extensa negociación de todos los aspectos del contrato y permitiendo el impulso y dinámica del sector $(2019$, p. 115)
De acuerdo con Brekoulakis y Thomas:

La globalización requiere la optimización en la asignación de recursos y la facilitación del comercio internacional. Los contratos estándares son usados en cada industria para ayudar en reducir costos. Los contratos estándar tienen una larga historia de uso en la industria de la construcción. Estos contratos ayudan a reducir los costos de transacción y brindan claridad y consistencia a las cláusulas (pp. 13-14).

Respecto de este fenómeno de proliferación de los contratos estándares en la industria de la construcción, Hernández Rodríguez señala que:

La evolución y transformación experimentada en el ámbito de la construcción no ha contado (...) con el respaldo doctrinal ni legal que el fenómeno merece. De nuevo, como ya viniese sucediendo en otros sectores del tráfico mercantil internacional, también en éste, han sido los propios particulares, especialmente a través de las asociaciones de profesionales y otras organizaciones internacionales, los que haciendo uso de su poder autonormativo han ofrecido, mediante la elaboración de contratostipo y condiciones generales, una regulación más acorde con sus propias necesidades y con las nuevas y peculiares características de los proyectos internacionales de construcción (2014, p. 162).

A su vez, Rodríguez Fernández ha señalado que:

Los modelos contractuales estandarizados se presentan, asimismo, como un uso del comercio en el ámbito de la ingeniería o construcción, pues se trata de uno de los sectores de la industria en que más se ha desarrollado la elaboración de contratos modelo. Ese proceso mediante el cual se utilizan los contratos modelo elaborados por diferentes instituciones de reconocida reputación en el ámbito internacional se ha complementado con un proceso de interpretación sistemática que de esos contratos ha seguido la jurisprudencia arbitral y en especial la proveniente de instituciones como la Cámara de Comercio Internacional y la Corte de Arbitramento Internacional de Londres. De manera tal que la práctica internacional referida al uso de esos modelos se encuentra plenamente reforzada por los diferentes pronunciamientos que se han hecho vía interpretación de los referidos modelos, todo lo cual genera una mayor certeza respecto de la interpretación de un referido término contractual utilizado por las partes (2006, p. 9). 
Los proyectos especiales de inversión pública y el modelo de ejecución de inversiones públicas: revisión de las herramientas que pueden emplearse para mejorar las contrataciones del Estado

Special public investment projects and the public investment execution model: review of the tools that can be used to improve government contracting

Como puede advertirse, a fin de hacer más eficiente la industria de la construcción y permitir la contratación transfronteriza, se vienen desarrollando diferentes contratos estándares internacionales que recogen las mejores prácticas internacionales de construcción. Estos contratos se encuentran en constante actualización para adaptarse a las innovaciones tecnológicas y procedimentales del sector construcción.

De acuerdo con Rameezdeen y Rodrigo (2005, pp. 31-40), los beneficios de usar contratos estándares internacionales en la industria de la construcción son los siguientes:

- Pueden ser usados para varios tipos de proyectos y requerimientos del cliente.

- Recogen prácticas de la industria y costumbres.

- Las partes se sienten cómodas con el hecho de que se trate de un modelo probado por un largo tiempo.

- Distribución de riesgos justa entre las partes.

- El precio del contrato suele ser menor dado que los contratistas no tienen que cotizar los riesgos adicionales asociados con la interpretación del contrato.

- Los costos de transacción en la negociación del contrato son reducidos.

Otro aspecto importante a destacar es que estos contratos son elaborados por expertos en el la industria de la construcción que entienden al contrato como un instrumento de gestión del proyecto, de alineamiento de incentivos y de administración de riesgos, antes que un conglomerado de complejas previsiones jurídicas.

Ahora bien, Chern señala que:

Con el gran número de contratos estándar que existen, muchas veces las partes se atreven a modificarlos de manera incorrecta o incluso los llenan de manera incorrecta, llevándolos a resultados desastrosos durante el proceso constructivo. Las disputas pueden generarse por la inconsistencia en del contrato modificado, dado que las condiciones particulares introducidas crean problemas donde nunca debieron existir (2016, p. 35).

En efecto, como se indicó anteriormente, existen diferentes contratos estandarizados, aplicables a diferentes tipos de proyectos, por ello, la elección del modelo correcto es compleja si antes no se ha definido la estrategia de contratación y no se tienen claro los requerimientos del propietario.

En esta línea, el Reglamento del DU 021-2020 señala que la elección de los contratos estandarizados por parte del PEIP se define en función de los objetivos estratégicos y la naturaleza del proyecto de inversión.

Considero que el centro de atención no debe estar puesto en el empleo del contrato estándar, sino en la definición de una correcta estrategia de contratación, basada en un profundo análisis y correcto entendimiento de las necesidades del proyecto y de la Entidad.
Existen diferentes modelos contractuales estandarizados, muchos de ellos elaborados sobre sistemas jurídicos distintos al peruano. Ello, sin perjuicio de que las asociaciones internacionales que promueven los diferentes contratos estandarizados en muchos casos están esforzándose por universalizar cada vez más estos contratos.

En el sector público peruano se tiene experiencia desde hace varios años en el uso de contratos FIDIC, como es el caso del Proyecto Expo Dubai y se tiene previsto el uso de estos contratos en el marco de algunos contratos de Gobierno a Gobierno, como es el caso del Aeropuerto Internacional de Chinchero. Recientemente, también se está empleando contratos NEC 3 ECC Opción $F$, correspondientes al PDS de gerencia de proyectos al riesgo, en los Juegos Panamericanos y en la Reconstrucción con Cambios; asimismo, contratos NEC ECS Opción A para subcontratación en la Reconstrucción con Cambios y contrato NEC TSC para la gestión de sedes deportivas en el Proyecto Legado de los Juegos Panamericanos.

Cualquiera sea el modelo de contrato internacional elegido, aun cuando tengan probado éxito en otras latitudes, este probablemente fracasará si las partes no conocen su filosofía, no interiorizan sus mecanismos y no logran interpretarlo correctamente. Se deben tener equipos preparados para ejecutar estos contratos.

De nada sirve un contrato muy sofisticado si las partes que lo suscriben no lo entienden y no logran ejecutarlo debidamente. Carece de sentido obligarse a un texto contractual estandarizado que no se conoce y las partes no han revisado y comprendido los pactos a los que están arribando. Esta situación puede generar que finalmente el contrato no cumpla sus objetivos y no sea un instrumento eficiente de gestión, sino únicamente una fuente de disputas.

Los contratos estándares tienen una gestión de riesgos y un alineamiento de intereses definidos que permiten su funcionamiento. Las partes deben evitar en lo posible modificar sus principales cláusulas, pues pueden desnaturalizarlos y perjudicar su funcionamiento. Si se realizan cambios sin 
entender la lógica de fondo de la estructura de estos contratos, se corren riesgos de generar diferentes tipos de controversias durante su ejecución o que se establezcan provisiones ineficientes o inequitativas.

Es común que las Entidades se sientan atraídas a modificar varias cláusulas de los contratos estándares para que estos calcen con los esquemas de la normativa de contratación pública peruana, normalmente para alterar la distribución de riesgos por el temor de que se cuestione que se ha favorecido al contratista. Para evitar ello, es importante que los funcionarios a cargo de la aprobación del desarrollo y aprobación del texto final del contrato se hayan capacitado en la filosofía y estructura de incentivos del contrato.

Otra dificultad para el empleo de estos contratos estándares es que varios de estos contratos no tienen una traducción oficial al español, por lo que las Entidades deberán realizar por sus propios medios, la traducción de estos contratos. En este proceso se puede alterar el sentido de algunas cláusulas, perjudicando el uso del modelo de contrato.

En suma, emplear contratos estándar que no se conocen puede presentar un alto riesgo. Previa a la adopción de este tipo de contratos se debe definir una estrategia de adiestramiento de los principales actores que intervendrán en su redacción, negociación y ejecución, incluyendo a los funcionarios del Sistema Nacional de Control.

En este escenario, considero relevante lo expuesto por Franco, cuando indica que:

El uso de contratos estándares internacionales no debe ser visto como un punto esencial. Los contratos pueden ser siempre mejorados, pero un buen contrato será aquel que calce con la normativa local, sea claro e incorpore las lecciones aprendidas de proyectos anteriores. Los contratos estándar internacionales, en cambio, son por definición deslocalizados, redactados de manera que puedan ser usados en muchos países, muchos no tienen una traducción oficial al español o esta es deficiente y no considera las particularidades de la realidad nacional ni incorporan las lecciones aprendidas de proyecto a proyecto. (...) En tal sentido, sería más adecuado generar mejores modelos de contratos nacionales, inspirados en las buenas prácticas locales e internacionales, que creer que un contrato modelo internacional hará una gran diferencia. Adicionalmente, al igual que con las normas, sin dejar de lado la importancia de contar con un buen contrato, lo principal es que el equipo que lo aplica sea razonable, competente, capacitado, empoderado y comprometido (2020b, pp. 17-18).

En este sentido, de cara a futuras modificaciones normativas, debe efectuarse un profundo análisis de nuestro mercado de compras públicas nacional, nuestra industria de la construcción y las normas imperativas de nuestro sistema jurídico y, sobre la base de ello, determinar qué contratos estándares internacionales se adaptan a nuestra realidad $\mathrm{o}$, mejor aún, sobre la base de la experiencia y la comprensión de las buena prácticas internacionales, desarrollar contratos modelo nacionales que brinden mayor claridad y eficiencia a la ejecución de las obras públicas.

\section{Metodología colaborativa de modelamiento digital de información para la construcción (BIM)}

EI DU 021-2020 establece que los PEIP utilizan la metodología colaborativa de modelamiento digital de la información para la construcción (BIM). A su vez, los Lineamientos definen al BIM como la "metodología de trabajo colaborativo basada en la aplicación de un conjunto de procesos, tecnologías y estándares que permiten formular, diseñar, construir, operar y gestionar la información de una infraestructura o edificación de forma colaborativa, en un entorno común de datos".

Ahora bien, de acuerdo con Murguía:

El BIM tiene aproximadamente 10 años en nuestra industria (...). El nicho de usuarios y empresas BIM en el mercado tienen experiencia en el uso de tecnologías y procesos de modelado y colaboración, sin embargo, estos están acotados a las etapas de diseño y construcción. Si se quiere avanzar como industria, se debe mirar hacia la integración de la información en entornos compartidos de datos en todo el ciclo de vida de los proyectos (2019, p. 20).

Conforme a ello, el BIM es una herramienta de trabajo colaborativo que se viene empleando en el sector privado y público en el Perú desde antes de los Juegos Panamericanos, pero que actualmente viene siendo impulsada por el Gobierno de manera progresiva para las obras públicas.

Así, el Plan Nacional de Competitividad y Productividad, aprobado mediante el Decreto Supremo 237-2019-EF, establece que el Plan BIM es una de las medidas necesarias para dotar al país de una infraestructura económica y social de calidad. En este sentido, se busca que el BIM sea un mecanismo que se inserte en la ejecución de los diversos proyectos de infraestructura pública en el país.

Por su parte, la Décimo Primera Disposición Complementaria Final del Texto Único Ordenado de la Ley 30225, Ley de 
Los proyectos especiales de inversión pública y el modelo de ejecución de inversiones públicas: revisión de las herramientas que pueden emplearse para mejorar las contrataciones del Estado

Special public investment projects and the public investment execution model: review of the tools that can be used to improve government contracting

Contrataciones del Estado, aprobado por Decreto Supremo 082-2019-EF, ha previsto que mediante decreto supremo se establezcan los criterios para la incorporación progresiva de herramientas de modelamiento digital de la información para la ejecución de los proyectos de infraestructura pública.

A su vez, el Decreto Supremo 289-2019-EF estableció disposiciones para la incorporación progresiva del BIM en los procesos de inversión pública de las entidades y empresas públicas sujetas al Sistema Nacional de Programación Multianual y Gestión de Inversiones. En dicha norma se ha definido al BIM como el "conjunto de metodologías, tecnologías y estándares que permiten formular, diseñar, construir, operar y mantener una infraestructura pública de forma colaborativa en un espacio virtual".

En la misma línea, el Plan de implementación y Hoja de ruta del Plan BIM Perú, aprobado mediante Resolución Directoral 002-2021-EF63.01, señala que el BIM no implica solo el uso de herramientas tecnológicas, sino que debe ser entendido como un conjunto de actividades colaborativas basadas en estándares que utilizan herramientas digitales para gestionar la información de una inversión.

Ahora bien, entre los beneficios de implementar el BIM se encuentra la digitalización de toda la información correspondiente a un determinado proyecto, garantizando la transparencia y trazabilidad. Asimismo, la integración en un único modelo de toda esta información, de manera tal que permita tener una visión completa del mismo para detectar oportunamente riesgos y adoptar decisiones. De igual forma, este entorno colaborativo genera la mejora de la calidad y eficiencia de las obras.

Aguilera y Segura señalan que el BIM:

Permite una mejor identificación de los requerimientos del contratante o del alcance de la infraestructura a desarrollar y, por ende, una adecuada estimación del presupuesto y plazo requeridos para su ejecución, además permite identificar, prevenir y solucionar tempranamente conflictos o diferencias de carácter técnico (2019).

En el mismo sentido, Salvatierra (2020) señala que el "BIM ayuda a reducir el costo y la duración final del proyecto, así como a minimizar las interferencias y errores de información en la etapa de construcción".

\section{A su vez, Giana y Vornicu (2020), señalan que:}

Aprovechar al máximo la metodología BIM implica procesos de construcción que cambian de un enfoque tradicional a enfoques de datos integrados. Sin embargo, para que los procesos digitales funcionen a máxima capacidad, requieren una reducción de la fragmentación horizontal y un mayor involucramiento de la cadena de suministro.

Como vemos, se está desarrollando un marco normativo que sienta las bases para la aplicación del BIM en las obras públicas de manera progresiva. Para ello, se requiere generar competencias en los funcionarios públicos en el empleo de esta herramienta de trabajo colaborativo. Este entrenamiento no solo debe incluir aspectos técnicos, pues el BIM no se resume en el uso de un software, sino el aprendizaje de la metodología de trabajo colaborativo.

Esta implementación progresiva se puede dar escogiendo determinadas Entidades que sirvan como piloto. Los PEIP, por la forma en la que están estructurados, su flexibilidad y las herramientas que integran el modelo de ejecución de inversiones, servirán como "laboratorios" para poner a prueba la normativa BIM en el Perú y recoger información que permita la mejora de la misma (pp. 114-115).

\section{Los Contratos entre Estados o Contratos de Gobierno a Gobierno}

De acuerdo con la Octava Disposición Complementaria Final del Reglamento del Decreto de Urgencia 021-2020, las Entidades del Gobierno Nacional que soliciten autorización para crear un PEIP pueden aplicar, a través del PEIP, el mecanismo de Contrato de Estado a Estado o de Gobierno a Gobierno.

La citada disposición agrega que el contrato entre Estados, "puede incluir la Asistencia Técnica Especializada en la Gestión de inversiones para la gestión y ejecución de las inversiones, la Metodología colaborativa de modelamiento digital de información para la construcción (BIM) y otras metodologías, y los Contratos estandarizados (...)".

Por su parte, la Exposición de Motivos del Decreto Supremo 179-2020-EF señala que resulta necesario que las Entidades que crean los PEIP "cuenten con mecanismos de contrataciones idóneos y compatibles con el modelo de ejecución de inversiones públicas como lo son los Contratos de Estado a Estado, para el cumplimiento de sus fines, metas y objetivos, que permitan la efectiva y oportuna satisfacción de las necesidades de su población objetivo. Teniendo en cuenta las características de las inversiones a ser ejecutadas por los PEIP son de gran envergadura, con el mecanismo de contratación de estado a estado también se puede realizar contrataciones estratégicas y 
planificadas, aprovechando la experiencia de otros Estados, debiendo enfocarse a ejecutar las inversiones y el gasto asignado para contrataciones en los plazos previstos, para satisfacer las necesidades de la población y los requerimientos para la competitividad del país."

En trabajos anteriores me he dedicado a los contratos entre Estados, así como a la forma en que estos se desarrollaron en los Juegos Panamericanos y ejecutaron los procesos de procura internacional ${ }^{(7)}$, por lo que en este punto únicamente me detendré sobre los puntos esenciales para el objetivo del presente artículo.

La modalidad de contratación entre Estados es un supuesto excluido del ámbito de aplicación de la Ley de Contrataciones del Estado. Se caracteriza por el hecho de que un Estado contrata bienes, servicios u obras que serán prestados por otro Estado conforme a los mecanismos y condiciones pactadas entre estos.

Debe ponerse en relevancia en el carácter contractual que la LCE da a esta modalidad, al margen de la denominación que se le asigne al documento en que se plasma: contrato, convenio, entendimiento, etc. Es este el motivo por el que se prevé expresamente como un "supuesto excluido del ámbito de aplicación de la normativa de contrataciones del Estado", pues, siendo un contrato celebrado por una Entidad para abastecerse de bienes, servicios u obras, con cargo a fondos públicos, sus particulares características han justificado que el legislador exonere a estos contratos de la aplicación de la ley de contrataciones del Estado.

Adicionalmente, podemos resaltar que la Exposición de Motivos del Decreto Legislativo 1444 desarrolla las ventajas de la contratación entre Estados, señalando que constituye un mecanismo efectivo para reducir el riesgo de incumplimiento, puesto que el Estado contratante no querrá ver comprometido su prestigio ni resquebrajar las relaciones comerciales y diplomáticas con el Perú. Asimismo, señala que mediante este mecanismo se elimina el riesgo de contratar con un proveedor internacional desconocido, pues el Estado extranjero debe evaluar previamente a los contratistas que ejecuten las prestaciones en su representación, empleando mecanismos tales como la revisión de su contabilidad, análisis de riesgos presentes y futuros, calculando el valor actual de dicha empresa, lo que le permite excluir a los proveedores con mayor riesgo y garantiza la idoneidad del proveedor.

Otro beneficio de esta modalidad es que la negociación de estos contratos abre un espacio para que los proveedores realicen mejoras a su propuesta, teniendo en cuenta sus conocimientos y experiencia sobre el objeto de la contratación, lo que evidentemente resulta en mayores beneficios para el país. Además, debido a que la negociación y selección de los proveedores estará a cargo del Estado extranjero, el Estado peruano reduce la cantidad de horas hombre para la selección.

Asimismo, la citada disposición establece las formalidades que deben seguirse previamente para celebrar un contrato entre Estados. La contratación debe ser autorizada por Decreto Supremo refrendado por el titular del sector correspondiente, declarando de interés nacional el objeto de la contratación. Para estos efectos, se debe cumplir con las siguientes condiciones:

a) Indagación de mercado que permita identificar a los Estados que puedan cumplir con el requerimiento del Estado Peruano.

b) Informe técnico-económico que compare las condiciones ofrecidas por los Estados interesados y evidencie las ventajas para el Estado peruano de contratar con otro Estado.

c) Informe de la oficina de presupuesto del sector correspondiente que señale que se cuenta con el financiamiento necesario para dicha contratación, salvo que se requiera concertar una operación de endeudamiento, en cuyo caso, la misma debe estar contemplada en el Programa Anual de Endeudamiento del año respectivo.

d) Declaratoria de viabilidad y/o aprobación en el marco del Sistema Nacional de Programación Multianual y Gestión de Inversiones, cuando corresponda.

Ahora bien, la Vigésima Primera Disposición Complementaria Final del TUO de la Ley de Contrataciones del Estado también establece que los contratos que se celebren pueden incluir cláusulas referidas a un plan de transferencia de conocimientos, plan de legado, implementación de una oficina de gestión de proyectos (PMO, por

(7) Véase, por ejemplo, Medina, J. C. (2019). Contratación Pública y la Experiencia de los Juegos Panamericanos. El modelo de gestión que promueve el gobierno. Revista de Derecho Administrativo, 18, 113-142.http://revistas.pucp.edu.pe/index.php/ derechoadministrativo/article/view/22859. 
Los proyectos especiales de inversión pública y el modelo de ejecución de inversiones públicas: revisión de las herramientas que pueden emplearse para mejorar las contrataciones del Estado

Special public investment projects and the public investment execution model: review of the tools that can be used to improve government contracting

sus siglas en inglés) y la obligación de remitir la documentación sobre la ejecución del contrato por parte del otro Estado al OSCE y el Sistema Nacional de Control, cuando estos lo soliciten.

La tendencia a celebrar contratos entre Estados está creciendo. Se han celebrado contratos entre Estados para la prestación de asistencia técnica en gestión de inversiones para la ejecución del Hospital Lorena y Sergio Bernales (Francia), los Juegos Panamericanos (Reino Unido), Reconstrucción con Cambios (Reino Unido), Aeropuerto Internacional de Chinchero (Corea del Sur) y la Carretera Central (Francia). Asimismo, se tiene previsto celebrar más contratos entre Estados para la ejecución de otros proyectos públicos, como es el caso de las Líneas 3 y 4 del Metro de Lima.

Como puede advertirse, este mecanismo excepcional de contratación viene siendo empleado con particular regularidad para la ejecución de importantes proyectos públicos, utilizando el modelo de asistencia técnica en gestión de inversiones (aunque no es el único modelo posible, pues este tipo de contratos pueden tener cualquier tipo de objeto contractual, ya sean bienes, servicios u obras).

Considero que los PEIP, conforme se adquiera experiencia nacional, deben evitar emplear la figura de los contratos entre Estados y, en cambio, emplear con sus propios recursos y personal el modelo de ejecución de inversiones. Los PEIP deben servir para poner a prueba las mejores herramientas y prácticas internacionales en gestión de proyectos, sin necesidad de acudir a otros Estados.

\section{Conclusiones y Recomendaciones}

El Modelo de Ejecución de Inversiones Públicas usado por los PEIP tiene diversas herramientas y facilidades que deben ser bien analizadas para su posible incorporación en la normativa de contrataciones del Estado o la mejora de la regulación de algunas figuras ya previstas.

De esta manera, al evaluar la mejora normativa de contrataciones del Estado recogiendo las experiencias recogidas en los últimos grandes proyectos públicos y la normativa especial (Contratos entre Estados y PEIP), se debe considerar la articulación de diferentes mecanismos que promuevan la eficiente gestión de las obras, tales como la implementación de una estructura que permita gestionar eficientemente el proyecto y la adopción de decisiones ágiles (como las PMO o las Junta de Cambios), herramientas que promuevan el trabajo colaborativo (como el BIM) y la definición de una correcta estrategia de contratación que permita trazar la ruta a seguir durante todo el proceso de contratación, sobre la base de la naturaleza y características del proyecto, la Entidad y el mercado.
Un concepto de fondo que subyace a varias de las herramientas del Modelo de Gestión de Inversiones Públicas es la colaboración, ya sea dentro de la misma Entidad, mediante la Junta de Cambios y las PMO, como con otros actores del proyecto, mediante el BIM y la elección de contratos estándares apropiados. Con la implementación de mecanismos que promuevan la colaboración se reducirá la litigiosidad, el ocultamiento de información y la cultura de culpar al otro.

De otro lado, resulta importante que se comparta la información de los contratos entre Estados. Se suelen crean regulaciones sobre la base del anunciado éxito de estos proyectos, pero no se ha plasmado cómo se ha logrado este éxito, qué retos se afrontaron, qué dificultades se superaron, qué oportunidades de mejora existen, en qué costos -de manera pormenorizada- se incurrieron, entre otros aspectos. Esta información detallada es muy necesaria si se piensan replicar los modelos empleados en estos contratos entre Estados. De otro modo, podríamos estar repitiendo errores o perdiendo la oportunidad de plantear mejoras, únicamente por no tener información completa. Se debe regular sobre evidencias claras.

Sin perjuicio de ello, creo que es importante rescatar las mejores prácticas empleadas en estos contratos y desarrollar capacidades en los funcionarios públicos, de manera tal que cada vez acudamos menos a los contratos entre Estados.

Finalmente, antes que centrarnos en adoptar algún contrato estándar internacional en específico como solución a todos los problemas de la obra pública, debemos conocer nuestro sistema, las prácticas de nuestro mercado, el nivel de madurez de las empresas de la industria de la construcción, las experiencias previas, entre otros aspectos, para poder decidir el contrato que más se adapte a cada obra, el que incluso podría ser un propio modelo peruano.

En efecto, los contratos estándares de construcción por sí solos no aseguran el éxito de un proyecto, por el contrario, un contrato que no se entiende y cuya filosofía no ha sido interiorizada por las partes puede ser fuente 
de constantes conflictos y trabar la ejecución del proyecto. Un contrato debe reducir costos de transacción, lo que no se logra cuando las partes han empleado un modelo de reconocido éxito internacional, pero que no saben cómo usarlo ni interpretarlo.

Antes que ello, la norma debe tener la flexibilidad necesaria para permitir que el funcionario público evalúe y decida la mejor estrategia de contratación para el proyecto. Ello implica elegir el PDS adecuado, el contrato que se adecúe a sus necesidades, decidir la estrategia de empaquetamiento, asignar correctamente los riesgos, entre otros aspectos. En este escenario, puede evaluarse incorporar nuevos PDS en la normativa de contrataciones del Estado, para que el funcionario público tenga mayores opciones para llevar a cabo el proyecto de manera eficiente.

\section{Referencias bibliográficas}

Aguilera, Z. \& Segura, R. (2019, 14 de octubre). El Estado inicia acciones para la implementación del BIM en el desarrollo de proyectos de infraestructura. APA Blog Style. http://blogs.gestion.pe/agendalegal/2019/10/el-estado-inicia-acciones-para-la-implementacion-delbim-en-el-desarrollo-de-proyectos-de-infraestructura.html

Block, K. \& Curran, L. (2010, 29 de septiembre). Liability of Construction Managers: Look to the Contract. New York Law Journal, 244(63). https://sprlaw.com/wp-content/uploads/2012/09/Liability-ofConstruction-Managers.pdf

Brekoulakis, S. \& Thomas, B. (2019). The Gide to Construction Arbitration ( $3^{\mathrm{a}}$ ed.). Law Business Research Ltd.

Chern, C. (2016). The Law of Construction Disputes. Informa Law (Second Edition). Editorial New York.

Franco, E. (2015). Arbitraje de construcción: aspectos de las distintas modalidades de contrato de construcción ( $2^{\mathrm{a}}$ ed.). Young Arbitration Review.

Franco, E. (2020a). La incorporación de procesos colaborativos en el contrato para lograr proyectos de construcción de alto desempeño. Derecho \& Sociedad, 55, 175-195. http://revistas.pucp.edu.pe/index. $\mathrm{php} /$ derechoysociedad/article/view/23241

Franco, E. (2020b). ¿Cuál es la clave para incrementar la capacidad y la calidad del gasto en la inversión pública? Revista Negocios Internacionales, 24, 269.

García, L. (2020). El contrato de Construcción Privado: Consecuencias jurídicas de la elección del Project delivery system. Editorial UPC.

Giana, P. \& Vornicu, R. (2020). The use of FAC-1 as a contractual integrator enhancing the use of BIM: a focus on the Liscate school in Italy. Derecho \& Sociedad, 55, 113-123. http://revistas.pucp.edu.pe/ index.php/derechoysociedad/article/view/23237/22226

Gobierno del Perú. (2019). Plan Nacional de Infraestructura para la Competitividad. https://www.mef.gob.pe/contenidos/inv_privada/ planes/PNIC_2019.pdf

Hernández, A. (2014). Los contratos internacionales de construcción "llave en mano". Cuadernos de Derecho Transnacional, 6(1), 161-235.
Latham, M. (1994). Constructing the team. Final Report of the Government/Industry Review of Procurement and Contractual Arrangements in the UK Construction Industry. HMSO.

Leee, L. (2015). International Construction Law. Editorial Willey Blackwell.

Lledó, P. (2017). Director de Proyectos (6. ${ }^{\mathrm{a}}$ ed.). Editorial USA.

Mckinsey Global Institute. (2017). Reinventing Construction: A route to higher productivity. McKinsey \& Company.

Medina, J. C. (2019). El Acuerdo de Gobierno a Gobierno y los Contratos NEC: ¿Soluciones a las deficiencias de la normativa de contrataciones del Estado que puedan ser replicadas por todas las entidades? IUS ET VERITAS, 58, 110-127. https:// doi.org/10.18800/iusetveritas.201901.006

Ministerio de Economía y Finanzas. (2021, 30 de abril). Resolución Ministerial 141-2021-EF/54. Disponen la publicación del Proyecto de Ley de Contrataciones del Estado en el portal institucional del Ministerio. https://busquedas.elperuano.pe/ normaslegales/disponen-la-publicacion-delproyecto-de-ley-de-contratacione-resolucionministerial-n-141-2021-ef54-1949114-1/

Murguía, D. (2019). Estudio de Macro Adopción BIM en Perú 2019. Departamento de Ingeniería, Pontificia Universidad Católica del Perú.

Presidencia de la República. (2020, 23 de enero). Decreto de Urgencia 021-2020. Decreto de Urgencia que establece el modelo de ejecución de inversiones públicas a través de proyectos especiales de inversión pública. https://busquedas. elperuano.pe/normaslegales/decreto-de-urgenciaque-establece-el-modelo-de-ejecucion-dedecreto-de-urgencia-n-021-2020-1848882-5/

Presidencia de la República. (2020, 22 de mayo). Decreto Supremo 119-2020-EF. Aprueban Reglamento de Proyectos Especiales de Inversión Pública en el marco del Decreto de Urgencia N ${ }^{\circ} 021$ 2020, Decreto de Urgencia que establece el modelo de ejecución de inversiones públicas a través de proyectos especiales de inversión pública y dicta otras disposiciones. https://busquedas.elperuano. pe/normaslegales/aprueban-reglamento-deproyectos-especiales-de-inversion-pub-decretosupremo-n-119-2020-ef-1866706-2/

Project Management Institute. (2017). Project Management Body of Knowledge (6. ${ }^{a}$ ed.). Project Management Institute.

Project Management Institute. (2011). Guía de los Fundamentos para la Dirección de Proyectos (guía PMBOK) (5. ${ }^{\text {a }}$ ed.). Project Management Institute, Inc. 
Los proyectos especiales de inversión pública y el modelo de ejecución de inversiones públicas: revisión de las herramientas que pueden emplearse para mejorar las contrataciones del Estado

Special public investment projects and the public investment execution model: review of the tools that can be used to improve government contracting

Rameezdeen, R. \& Rodrigo, A. (2005). Modification to standard forms of contract: the impact on readability. Austrasian Journal of Construction Economics and Building, 14(2), 31-40. https://doi. org/10.5130/AJCEB.v14i2.3778

Rodríguez, M. (2006). El Contrato Internacional de Construcción: Aspectos Generales. Revista Mercatoria, 5(1), 1-29.

Salvatierra, J. L. (2020, 6 de marzo). ¿BIM sin Lean? APA Blog Style. https://negocioyconstruccion.cl/ bim-sin-lean/.
Spittler, J. \& Nelson, E. (2011). Where is Project Delivery Headed? AACE International Transactions.

The Construction Management Association of America. (2012). An Owner's Guide to Project Delivery Methods. Advancing Professional Construction and Program Management Worldwide.

Valdés, J. (2008, 13 de agosto). La PMO ágil: un enfoque súper rápido para crear una PMO efective para su organización. APA Style Blog. https://www.pmi.org/learning/library/agile-project-management-officeexpectations-7069. 